\title{
A Study of Abdomenal Pain in Children
}

\author{
Shakya KN, ${ }^{1}$ Dongol UMS, ${ }^{2}$ Khadka SB ${ }^{3}$ \\ 'Department of Pediatrics, ${ }^{2}$ Department of Surgery, ${ }^{3}$ Department of Emergency Kathmandu Medical \\ College, Kathmandu, Nepal
}

\begin{abstract}
Pain abdomen is a common pediatric complaint that brings patient to the hospital in Nepal. Knowledge about its etiology and frequency helps in its evaluation and management. The present study was undertaken to find out the causes and their frequency of pain abdomen in Nepali children. Children with pain abdomen presenting at the emergency room and pediatric outpatient department of Kathmandu Medical College, Kathmandu from January, 2006 to December 2007 were clinically evaluated and investigated to find out the causes and frequency of their pain abdomen. The outcomes were tabulated and analyzed for interpretation. Of 444 patients attended, 356 completed investigations and came for follow up. Cause of pain abdomen was apparent in 117 (32.9\%) only. 91.5\% were medical causes, comprising predominantly of diarrheal diseases (28.3\%), infantile colic $(9.4 \%)$, urinary tract infection $(7.7 \%)$ and acid peptic disease $(6.8 \%) .8 .5 \%$ causes were related to surgical conditions, which needed operative management. Secondary or extra-abdominal causes were found in 20 cases (17.1\%). Pneumonia (2), functional (5), vulvovaginitis (2) and infantile colic (11) were predominant causes. Our study showed that the causes of pain abdomen in children were predominantly medical. Gastroenteritis was the most frequent cause. Secondary causes, including functional and emotional causes were infrequent. Small percentage needing surgical management formed a diagnostic challenge.
\end{abstract}

Key words: abdomen, children, gastroenteritis, pain

\section{INTRODUCTION}

Pain abdomen is one of the most common and frequent complaint in children. ${ }^{1}$ About $10 \%$ of all children attending the emergency room have complaints referable to the abdomen. ${ }^{2}$ The cause of pain abdomen may be a trivial and self limiting condition or it may herald a medical or surgical emergency. Differentiating abdominal pain because of benign conditions from those that require prompt medical or surgical intervention is an enormous problem. ${ }^{3}$ Knowledge about the various etiologies of abdominal pain and their frequency helps to provide a clinical guideline for evaluation of a child with abdominal pain and to identify patients who will not improve without medical or surgical intervention. Published reports on abdominal pain in Nepali Children are scarce and those about its causes and frequency are almost non-existent. ${ }^{4}$ So, the present study was

\footnotetext{
Correspondence:

Dr. Kashyap Narsingh Shakya

Department of Pediatrics

Kathmandu Medical College, Kathmandu, Nepal

Phone: 9841545346

E-mail: nphl@wlink.com.np
} 
Shakya et al. A Study of Pain Abdomen in Children

undertaken to list the various causes of pain abdomen in Nepali children and to find out their frequency of occurrence.

\section{MATERIAL AND METHODS}

This is a prospective, observational study conducted in the children with pain abdomen presenting at the emergency room and the pediatric outpatient department of Kathmandu Medical College, Kathmandu from January 2006 to December 2007 were included in the study. Inclusion criteria was age below 15 years and site of pain below costal margins and above inguinal ligaments. Case exclusion criteria were considered met when pain was vague and inconsistent or not present at the time of clinical examination and following subsequent observation. Clinical examination was done in each case followed by routine stool, urine and blood investigations. Urine culture and sensitivity, abdominal ultrasonogram, radiological investigations and endoscopic examinations were done according to case merit. Treatment and observations were done and follow up visits arranged on response basis. All apparent causes of pain abdomen were recorded, tabulated and analyzed for interpretation by using appropriate statistical values.

\section{RESULTS}

A total of 444 children attended with complaints of pain abdomen during the study period. 88 patients were lost to follow up. Of 356 children investigated identifiable causes for pain abdomen were found in 117 (32.9\%) cases. The demographic profile of those patients with identifiable cause have shown male predominance (Table 1). Male children (62.53\%) slightly outnumbered the females with a male female ratio of $1.1: 1$. The age distribution shows preponderance of 6-10 year olds $(53 \%)$ with mean age 8.7 years (Table 1 ).

Maximum number of causes of pain abdomen (59.1\%) were from gastrointestinal system which together with Hepatobiliary $(6.8 \%)$ and genitourinary causes $(12 \%)$ constituted three fourth (76. 9\%) of all causes (Table 2). Secondary causes (Pneumonia 2, functional 5, vulvovaginitis 2 , infantile colic 11 ) were observed in 20 $(17.1 \%)$ cases, in whom the causes were considered extra-abdominal. According to the system wise, pain abdomen comprises medical $(91.5 \%)$ and surgical $(8.5 \%)$, gastoenteritis being the most common and frequent cause of pain abdomen (Table 3,4). On the other hand, a case of lymphoma of mesenteric lymph nodes, a rare case, was also seen. Surgical causes $(10$, $8.5 \%$ ) were responsible in less than one tenth cases of abdominal pain in our study (Table 5). All those cases needed operative treatment.
Table 1. Demographic profile of the patients with identifiable cause for pain abdomen

\begin{tabular}{lcc}
\hline Parameters & No. (\%) \\
\hline Male & $62(53)$ \\
Female & $55(47)$ \\
Age range & 4 months -15 year \\
Mean age & & 8.7 year \\
Age group & $0-5$ years & $18(15.4)$ \\
& $6-10$ years & $62(53.0)$ \\
& 11-15 years & $37(31.6)$ \\
\hline
\end{tabular}

Table 2. Causes of pain abdomen

\begin{tabular}{lc}
\hline Causes & No. (\%) \\
\hline Gastrointestinal & $68(58.1)$ \\
Genitourinary & $14(12.0)$ \\
Hepatobiliary & $8(6.8)$ \\
Drugs & $5(4.3)$ \\
Hematological & $4(3.4)$ \\
Pulmonary & $2(1.7)$ \\
Miscellaneous & $16(13.7)$ \\
Total & $117(100)$ \\
\hline
\end{tabular}

Table 3. Causes of pain abdomen according to different system (n-117)

\begin{tabular}{ll}
\hline Causes & No. (\%) \\
\hline Medical Causes & $107(91.5)$ \\
Gastroenteritis & $21(18)$ \\
Giardiasis/amebiasis & $12(10.3)$ \\
Helminthiasis & $6(5.1)$ \\
Food poisoning & $2(1.7)$ \\
Lactose intolerance & $2(1.7)$ \\
Acute peptic disease & $8(6.8)$ \\
Constipation & $6(5.1)$ \\
Mesenteric lymphadenitis & $6(5.1)$ \\
Hepatitis & $4(1.7)$ \\
Cholecystitis & $2(5.1)$ \\
Urinary tract infection & $9(0.9)$ \\
Vulvovaginitis & $2(6.8)$ \\
Pneumonia & $2(3.4)$ \\
Henoch-Schonlein purpura & $4(1.7)$ \\
Drugs (lbuprofen 4, Salicylates 1$)$ & $5(1.7)$ \\
Infantile colic & $11(12)$ \\
Functional pain & $5(7.7)$ \\
Surgical causes & $10(8.5)$ \\
Total & $117(100)$ \\
\hline
\end{tabular}


Shakya et al. A Study of Pain Abdomen in Children

Table 4. Common causes of pain abdomen according to frequency

\begin{tabular}{ll}
\hline Causes & No. (\%) \\
\hline Gastroenteritis & $21(18)$ \\
Giardiasis/amebiasis & $12(10.3)$ \\
Infantile colic & $11(9.4)$ \\
Urinary tract infection & $9(7.7)$ \\
Acid peptic disease & $8(6.8)$ \\
Mesenteric lymphadenitis & $6(5.1)$ \\
Helminthiasis & $6(5.1)$ \\
Constipation & $6(5.1)$ \\
Drugs & $5(4.3)$ \\
Functional pain & $5(4.3)$ \\
Other & $28(23.9)$ \\
\hline Total & $117(100)$ \\
\hline
\end{tabular}

Table 5. Surgical causes of pain abdomen

\begin{tabular}{lc}
\hline Causes & No. (\%) \\
\hline Urinary calculi & $3(30)$ \\
Abdominal trauma & $2(20)$ \\
Appendicitis & $2(20)$ \\
Cholelithiasis & $2(20)$ \\
Lymphoma of mesenteric lymph nodes & $1(10)$ \\
\hline Total & $10(100)$ \\
\hline
\end{tabular}

\section{DISCUSSION}

Causes of pain abdomen can be many and varied. Parents tend to be complacent as pain subsides and refuse investigations to find out the etiology of pain. In the present study 88 cases $(19.8 \%)$ were lost to follow up. Moreover, it is difficult to find a specific cause for every pain abdomen ${ }^{2}$ and the diagnostic yield may be small, even with the invasive procedures ${ }^{5}$. In the present study, only in one third cases $(32.9 \%)$ recognizable causes for pain abdomen were found. Many cases of acute abdominal pain resolve spontaneously before a cause could be found and such a situation is disturbing to parents as well as the physician. ${ }^{6}$ Among the identifiable causes $91.5 \%$ were due to medical conditions comparable to other studies. This preponderance of medical causes for pain abdomen is documented. ${ }^{7}$ Less than a quarter of total cases $(17.1 \%)$ were found to be due to secondary or extra-abdominal causes and unsuspected pneumonia was revealed in two cases $(1.7 \%)$, which corresponded with reports by others. ${ }^{8,9}$ Pneumonia( 15 out of 51 cases) was the most frequent extra-abdominal cause of pain abdomen found in another study. ${ }^{10}$ Infantile colic $(9.5 \%)$ observed in our study is considered to be due to psychosocial factors, a failure of parent infant interaction and milk allergy. ${ }^{11,12}$ Diarrheal diseases, urinary tract infection and acute peptic disease observed in our study as frequent causes of pain abdomen in children are also well documented in other literature. ${ }^{7,13}$ Distinguishing features of acute gastrointestinal tract pain in children has also been described. ${ }^{14}$ Helminthiasis $(5.1 \%)$ although considered a common cause of pain abdomen in Nepali children was found less frequently in our study. It may be due to the fact that this study was carried in urban population. Furthermore, only severe helminthiais only become symptomatic. ${ }^{15}$ Other causes like abdominal epilepsy, abdominal migraine, irritable colon and dyspepsia were not seen in the present study reflecting low incidence of functional and emotional causes for abdominal pain in Nepali children (4.3\%), as was reported from India. ${ }^{16-19}$

Surgical conditions were found responsible for pain abdomen in less than one tenth cases $(8.5 \%)$, although they needing rapid diagnosis for preventing morbidity. Early exclusion of surgical cause has been emphasized, which holds true, as all our surgical cases needed operative treatment. In our experience, trans-abdominal ultrasound examination was helpful for early diagnosis. Evaluation by computed tomography has been used by others, especially in atypical cases..$^{20-22}$ It has been estimated that less than $5 \%$ of children with pain abdomen will ultimately require abdominal exploration. ${ }^{23}$ However, differentiating abdominal pain that require prompt surgical intervention from pain because of nonsurgical conditions often is challenging. ${ }^{24}$ No case of congenital abnormality, intussusceptions or intestinal obstruction causing pain abdomen was observed in the present study, which may be due to lack of pediatric surgical unit in our hospital.

Periodic appraisal and re-evaluation of causes and their frequency helps in planning investigations and forming clinical guidelines for management of children with abdominal pain. ${ }^{6,24}$

\section{CONCLUSION}

Pain abdomen in children was most commonly due to medical causes. Gastroenteritis was observed as the most frequent cause. Secondary or extra-abdominal causes comprised less than one quarter of all causes. Surgical conditions needed early exclusion and their differentiation from medical causes were challenging. They were responsible in about one tenth cases only. Knowing causes and frequency helps in focused investigation and clinical management of abdominal pain in children. 


\section{REFERENCES}

1. King BR. Acute abdominal pain. In: Hoekelman RA, editor. Primary pediatric care. 3rd ed. St. Louis: Mosby; 1997. p. 1819.

2. Stevenson RJ. Management of child with acute abdominal pain. In: Rudolph AM, Margaret KH, Lister G. Siegel NJ, editors. Rudolph's Pediatrics 21st ed. New York: Mc GrawHill Medical Publishing Division; 2003. p. 1354-63.

3. Jones PF. Active observation in management of acute abdominal pain in childhood. Br Med J 1976;2:551-3.

4. Mason JD. The evaluation of acute abdominal pain in children. Emerg Med Clin North Am 1996;14:629-43.

5. Fraser GC. Children with acute abdominal pain: Taking a reasonable approach. Can Fam Physician 1993;39:1461-7.

6. Buchert GS. Abdominal pain in children: an emergency practitioner's guide. Emerg Med Clin North Am 1989;7:497517.

7. Leung AKC, Sigalet DL. Acute abdominal pain in children. Am Fam Physician 2003;67:2321-6.

8. Ravichandran D, Burge DM. Pneumonia presenting with acute abdominal pain in children. Br J Surg 1996;83:1707-8.

9. Homier V, Bellavance C, Xhignesse M. Prevalance of pneumonia in children under 12 yrs of age who undergo abdominal radiography in the emergency department. Can J Emerg Med 2007;9(5):347-51.

10. Tsalkidis A, Gardikis S, Cassimos D, Kambouri K, Tsalkidou E, Deftereos $S$, et al. Acute abdomen in children due to extraabdominal causes. Pediatr Int 2008;50(3):315-8.

11. Wade S, Kilgour T. clinical review: infantile colic. Br Med J 2001;323:437-40.

12. Hill DJ, Hosking CS. Infantile colic and food hypersensitivity J Pediatr Gastroenterol Nutr 2002;30(S1):67-76.

13. Sims DG, Alexander FW. Acute abdominal pain in childhood. Br Med J 1976;2:880-1.
14. Wyllie R. The digestive system. In: Beherman RE, Kligman RM, Jenson HB, editors. Nelson Textbook of Pediatrics. 17th ed. Philadelphia: Saunders; 2004. p. 1197-204.

15. Weinberg A, Levin MJ. Infections: parasitic and mycotic. In: Hay, Jr WW, Levin MJ, Sondheimer JM, Deterding RR. editors. Current Diagnosis and treatment in Pediatrics. 18th ed. New York: Lange Medical Books/McGraw-Hill; 2007. p. 1214-52.

16. Nixon H, O'Donnell B. Recurrent Abdominal Pain. In: The essentials of Pediatric Surgery 3rd ed. London: William Heinemann Medical Books Ltd.; 1976. p. 146-53.

17. Abu-Arafeh I. Headache and Migraine. In: McIntosh N, Helms P, Smyth R, editors. Forfar and Arneil's Textbook of Pediatrics. 6th ed. Edinburgh: Churchill Livingstone; 2003. p. 951-7.

18. Loening - Bauke V. Dyspepsia in children. Digestive Health Matters 2006; 2(3):1-12.

19. Ramkrishnan MS. Chronic abdominal pain in children. In: Ramkrishnan MS, Dayalan N, Ravikumar VR, Varma KK, ThambiDorai CR, editors. Pediatric surgery. 1st ed. New Delhi: Jaypee Brothers; 1966. p. 290-2.

20. Neblett WW. Acute abdominal conditions in children and adolescents. Surg clin N Am 2006;68:415-30.

21. Ng CS. Evaluation of early abdominopelvic computed tomography in patients with acute abdominal pain of unknown cause: prospective randomized study. BMJ 2002;325:1387-90.

22. Glund LL, Rask-Madsen J. unusual causes of abdominal pain. Best Pract Res clin Gastroenterol 2005;19:175-310.

23. Farthing MJG. Pearls and pitfalls in the diagnosis of the acute abdomen. Ind J Gastrointerol 2006;25(S1):33-5.

24. Caty MG, Azizkhan RG. Acute surgical conditions of the abdomen. Pediatr Ann 1994;23:192-201. 